\title{
Hematuria following Botox treatment for upper limb spasticity: a case report
}

This article was published in the following Dove Press journal:

Journal of Pain Research

14 September 2015

Number of times this article has been viewed

\author{
Tony CT Lo',* \\ Stephen TYeung ${ }^{2, *}$ \\ Sujin Lee' \\ Eric Y Chang'
}

'Department of Physical Medicine and Rehabilitation and Neurological

Surgery, ${ }^{2}$ Institute of Memory Impairment and Neurological Disorders, University of California, Irvine, CA, USA

*These authors contributed equally to this work

Video abstract

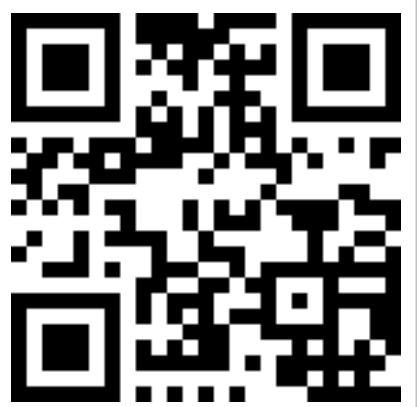

Point your SmartPhone at the code above. If you have a QR code reader the video abstract will appear. Or use: http://youtu.be/WkPSQBhjOLk
Correspondence: Eric Y Chang Department of Physical Medicine and Rehabilitation, University of California, Irvine, I0I The City Drive South, Orange, CA 92868, USA

Tel + I 7144566668

Fax +l 7144566557

Email ericyaochang@yahoo.com
Abstract: Hematuria is a documented side effect of botulinum toxin injection and has only been reported when it is used for overactive bladder. Here we report a rare case of hematuria following onabotulinumtoxin A (Botox) injection for upper limb spasticity in a 29-year-old male with a history of traumatic brain injury and hemophilia. Hematuria resolved without further complication after self-injection of factor VIII as recommended by his hematologist. Botulinum toxin binds peripheral cholinergic nerve endings to prevent acetylcholine and norepinephrine exocytosis. Studies have shown that both of these compounds are involved in antifibrinolytic activation, suggesting botulinum toxin may play a role in the coagulation cascade by preventing formation of fibrin. This is further supported by resolution of hematuria in our patient after self-injection of factor VIII. As such, botulinum toxin injection may result in mild spontaneous hemorrhage in patients with underlying hematological deficiencies. Further studies are needed to elucidate its effects in coagulation.

Keywords: hematuria, botulinum toxin, upper limb spasticity, hemophilia

\section{Introduction}

Spasticity is a common neurological complication following central nervous system injuries such as traumatic or acquired brain and spinal cord injury. Indications for the treatment of spasticity include pain, function limitations, contracture prevention, and positioning assistance. Non-pharmacological modalities include proper positioning of the affected body region, range of motion/stretching exercises, splinting, or casting. Pharmacological agents include baclofen, clonidine, tizanidine, dantrolene, and benzodiazepines. However, the use of medications can be limited by cognitive and sedative side effects. Thus, the use of botulinum toxin (BonT) type A and B injections has been preferred for localized spasticity.

BonT is derived from the Clostridium botulinum neurotoxin that causes botulism. It binds presynaptic peripheral cholinergic nerve endings, acting intracellularly to cleave polypeptides involved in acetylcholine and norepinephrine exocytosis. ${ }^{1,2}$ In multiple systematic reviews and clinical trials, BonT used for various muscle tone disorders has proven to reduce spasticity, increase range of motion, improve positioning, and decrease pain. ${ }^{3-6}$ BonT is also approved for the treatment of blepharospasm, overactive bladder, chronic migraine, axillary hyperhidrosis, and strabismus.?

As with any pharmacological therapies for spasticity, onabotulinumtoxin A (Botox) is also associated with adverse effects such as nausea, fatigue, bronchitis, muscular weakness, and pain. ${ }^{7,8}$ In cases of detrusor overactivity, there have been reports of hematuria associated with BonT injections. ${ }^{9}$ Although this may be a result of mucosal trauma from the 
injection itself, studies have demonstrated a greater incidence of hematuria in BonT groups compared with placebo and also with higher drug concentrations. ${ }^{10,11}$ However, there are few to no reports of hematuria when it is used for spasticity in the upper limb. This case documents the unusual side effect of hematuria following BonT injection for upper limb spasticity.

\section{Case report}

A 29-year-old male with a history of hemophilia A presented to an outpatient specialty clinic for right upper limb spasticity secondary to traumatic brain injury. The Institutional Review Board of University of California, Irvine, Orange, CA, USA approved collection of patient data with written consent. The patient reported dull pain localized to his right wrist radiating up to the shoulder (rated 6-8/10 on a numeric rating scale) and associated paresthesias of the second to fifth digits. The pain improved with massage, but was exacerbated with writing and long distance stick shift driving involving finger flexion with repetitive elbow and shoulder joint motions. This condition was previously treated with 140 units of BonT, resulting in limited improvement of his pain. Examination of his right upper limb revealed increased tone (rated 1 on the Modified Ashworth Scale) with shoulder internal rotation and adduction, elbow flexion, and wrist flexion. He had no atrophy of the right thenar eminence, but had decreased strength of the right finger and thumb. Sensation was intact, and Tinel's and Phalen's tests were negative. The previous diagnosis of pain due to right upper limb spasticity was confirmed, and was further treated with a total of 500 units of onabotulinumtoxin A (100 units for right anterior deltoid, 50 units for pectoralis, 100 units for biceps, 75 units for brachioradialis, 50 units for brachialis, 75 units for extensor carpi radialis, 25 units for extensor carpi ulnaris, and 25 units for flexor digitorum superficialis). After a month, his pain decreased to 4-5/10 on the numeric rating scale. However, a day after leaving the clinic, the patient reported developing hematuria, which lasted 4-5 days and resolved upon self-infusion of factor VIII as recommended by his hematologist. Of note, he had not had hematuria in the past and does not require regular infusions. Also, he did not report any trauma. Given his history of bladder stones, he was further evaluated in the emergency room, where the workup did not show evidence of cystoliths or urinary tract infection.

\section{Discussion}

BonT preferentially binds and penetrates peripheral cholinergic nerve endings, acting intracellularly on metalloendoprotease to cleave polypeptides involved in acetylcholine exocytosis. ${ }^{1}$ By preventing acetylcholine release from the presynaptic membrane, BonT blocks nerve impulses involved in muscle contractions, which induces chemodenervation resulting in decreased muscle tone. ${ }^{12}$ BonT also causes muscle fiber atrophy and reduces the potential size of motor units, leading to weakness in muscle strength. Studies have demonstrated the clinical effect of BonT in patients with upper limb spasticity from traumatic brain injury and stroke resulting in improved range of motion as well as in Modified Ashworth Scale rating and muscle tone. ${ }^{13,14}$ Various side effects, including pain, fatigue, muscle weakness, bronchitis, and upper respiratory tract infections have been reported with BonT injection for upper limb spasticity, but little is known of BonT-associated hematuria when used for spasticity in the upper limb.

This report illustrates hematuria that resolved after selfinfusion of factor VIII. As such, BonT may play a role in the intrinsic coagulation cascade, resulting in or exacerbating spontaneous hemorrhage in those with underlying hematological deficiencies. Acetylcholine is suggested to be involved in the activation of antifibrinolytic compounds. ${ }^{15}$ Another study has reported similar mechanisms, implying that acetylcholine results in increased thrombin release and prothrombin gene expression. ${ }^{16}$ Additionally, higher concentrations of the toxin are able to block norepinephrine exocytosis from other nerve endings. ${ }^{2}$ A report has shown norepinephrine increases thrombin and fibrin formation via $\beta 2$-adrenergic receptors. ${ }^{17}$ Another study demonstrated similar findings when norepinephrine was infused into patients with traumatic brain injury, resulting in a reduction in platelets possibly due to thrombus formation. ${ }^{18}$ As such, by blocking norepinephrine release, higher levels of BonT may indirectly prevent clot formation, resulting in spontaneous hemorrhage. Therefore, it is hypothesized that by reducing the release of acetylcholine and norepinephrine, BonT causes spontaneous hemorrhage through an anticoagulation effect.

Furthermore, our patient had a history of factor VIII deficiency, which imposes a greater risk for spontaneous bleeding. Hemophilia is an inherited X-linked disorder associated with a defect of clotting factor VIII or IX. Spontaneous hematuria is relatively common in patients with hemophilia, and theorized to be due to tubular damage caused by immune complexes. ${ }^{19}$ This, in sequence with the negative effect of BonT on coagulation, suggests that its use may convert what typically occurs as clinically insignificant microhematuria into gross hematuria by destabilizing clot formation that is used to heal the damage that occurs at baseline in patients with hemophilia.

Although it is difficult to explain systemic reactions caused by localized BonT injection, some studies have 
shown subclinical effects of the toxin distant from the injection site. Post-marketing surveillance reports have illustrated toxin spread in adults treated for spasticity, such as dysphagia and breathing difficulties after treatment of cervical dystonia. ${ }^{7}$ Likewise, a double-blind, placebo-controlled trial reported an increased incidence of dry mouth in patients treated with BonT for upper limb spasticity. ${ }^{20}$ Additional findings were seen in a study that demonstrated an increased average jitter value on single fiber electromyography of the extensor digitorum after patients with craniocervical dystonia and hemifacial spasms received twice the dose of BonT injections. ${ }^{21} \mathrm{~A}$ similar dose-related response was seen in our case as the patient was able to tolerate lower doses of the toxin without complication, but developed hematuria with increased doses. Furthermore, dose-dependent responses have been observed in clinical accounts involving generalized weakness after upper limb injection, and detrusor weakness in patients with detrusor hyperreflexia. ${ }^{22,23}$ These studies suggest that despite localization, BonT may enter the systemic circulation, resulting in generalized effects in a dose-dependent manner.

\section{Conclusion}

Clinically, it is critical to consider the potential systemic effects with localized BonT injections. It can be hypothesized that BonT has a negative effect on the coagulation cascade, given the effects of acetylcholine and norepinephrine on thrombin and fibrin. Therefore, it is crucial that clinicians are aware of the bleeding risk with a dosage increase, especially in patients with pre-existing hematological disorders. Additional studies should be undertaken to further elucidate the effect of BonT in the coagulation pathway as well as to determine optimal doses and techniques that may avoid these complications.

\section{Disclosure}

Financial disclosure statements have been obtained, and no conflicts of interest have been reported by the authors or by any individuals in control of the content of this article. Portions of this study have been presented in poster form at the 2015 Association of Academic Physiatrists Annual Meeting in San Antonio, TX, USA, on March 12, 2015.

\section{References}

1. Simpson LL. Identification of the major steps in botulinum toxin action. Annu Rev Pharmacol Toxicol. 2004;44:167-193.

2. Habermann E, Dreyer F. Clostridial neurotoxins: handling and action at the cellular and molecular level. Curr Top Microbiol Immunol. 1986;129: 93-179.
3. Baker JA, Pereira G. The efficacy of botulinum toxin A for spasticity and pain in adults: a systematic review and meta-analysis using the Grades of Recommendation, Assessment, Development and Evaluation approach. Clin Rehabil. 2013;27:1084-1096.

4. Nalysnyk L, Papapetropoulos S, Rotella P, Simeone JC, Alter KE, Esquenazi A. OnabotulinumtoxinA muscle injection patterns in adult spasticity: a systematic literature review. BMC Neurol. 2013;13:118.

5. Simpson DM. Clinical trials of botulinum toxin in the treatment of spasticity. Muscle Nerve Suppl. 1997;6:S169-S175.

6. Wissel J, Muller J, Dressnandt J, et al. Management of spasticity associated pain with botulinum toxin A. J Pain Symptom Manage. 2000;20:44-49.

7. Allergan. Botox injection [Prescribing information]. Available from: http://www.allergan.com/assets/pdf/botox_pi.pdf. Accessed October 4, 2014.

8. Sheean G. Botulinum toxin treatment of adult spasticity: a benefit-risk assessment. Drug Saf. 2006;29:31-48.

9. Dmochowski R, Sand PK. Botulinum toxin A in the overactive bladder: current status and future directions. BJU Int. 2007;99:247-262.

10. Schurch B, de Seze M, Denys $P$, et al. Botulinum toxin type A is a safe and effective treatment for neurogenic urinary incontinence: results of a single treatment, randomized, placebo controlled 6-month study. J Urol. 2005;174:196-200.

11. Altaweel W, Mokhtar A, Rabah DM. Prospective randomized trial of $100 \mathrm{u}$ vs $200 \mathrm{u}$ Botox in the treatment of idiopathic overactive bladder. Urol Ann. 2011;3:66-70.

12. Sheean G. Botulinum toxin for the treatment of musculoskeletal pain and spasm. Curr Pain Headache Rep. 2002;6:460-469.

13. Yablon SA, Agana BT, Ivanhoe CB, Boake C. Botulinum toxin in severe upper extremity spasticity among patients with traumatic brain injury: an open-labeled trial. Neurology. 1996;47:939-944.

14. Brashear A, Gordon MF, Elovic E, et al. Intramuscular injection of botulinum toxin for the treatment of wrist and finger spasticity after a stroke. N Engl J Med. 2002;347:395-400.

15. Golyshenkov SP, Skipetrov VP. [Effect of acetylcholine and atropine on the release by the intestine of hemocoagulating substances into blood]. Fiziol Zh SSSR Im I M Sechenova. 1982;68:1240-1245. Russian.

16. Glazner GW, Yadav K, Fitzgerald S, Coven E, Brenneman DE, Nelson PG. Cholinergic stimulation increases thrombin activity and gene expression in cultured mouse muscle. Brain Res Dev Brain Res. 1997;99:148-154.

17. von Kanel R, Mills PJ, Ziegler MG, Dimsdale JE. Effect of beta2adrenergic receptor functioning and increased norepinephrine on the hypercoagulable state with mental stress. Am Heart J. 2002;144: 68-72.

18. Tschuor C, Asmis LM, Lenzlinger PM, et al. In vitro norepinephrine significantly activates isolated platelets from healthy volunteers and critically ill patients following severe traumatic brain injury. Crit Care. 2008;12:R80.

19. Benedik-Dolnicar M, Benedik M. Haematuria in patients with haemophilia and its influence on renal function and proteinuria. Haemophilia. 2007;13(5):489-92.

20. Brashear A, McAfee AL, Kuhn ER, Fyffe J. Botulinum toxin type B in upper-limb poststroke spasticity: a double-blind, placebo-controlled trial. Arch Phys Med Rehabil. 2004;85:705-709.

21. Girlanda P, Vita G, Nicolosi C, Milone S, Messina C. Botulinum toxin therapy: distant effects on neuromuscular transmission and autonomic nervous system. J Neurol Neurosurg Psychiatry. 1992;55: 844-845.

22. Bhatia KP, Munchau A, Thompson PD, et al. Generalised muscular weakness after botulinum toxin injections for dystonia: a report of three cases. J Neurol Neurosurg Psychiatry. 1999;67:90-93.

23. Popolo GD. Botulinum-A toxin in the treatment of detrusor hyperreflexia. Neurourol Urodyn. 2001;20:522-524. 
Journal of Pain Research

\section{Dovepress}

\section{Publish your work in this journal}

The Journal of Pain Research is an international, peer-reviewed, open access, online journal that welcomes laboratory and clinical findings in the fields of pain research and the prevention and management of pain. Original research, reviews, symposium reports, hypothesis formation and commentaries are all considered for publication.

The manuscript management system is completely online and includes a very quick and fair peer-review system, which is all easy to use. Visit http://www.dovepress.com/testimonials.php to read real quotes from published authors.

Submit your manuscript here: http://www.dovepress.com/journal-of-pain-research-journal 